\title{
Epidemiological Study of Canine hypothyroidism in Chhattisgarh state, India
}

\author{
B. Roopali ${ }^{1 *}$, S. Roy $^{1}$, M. Roy $^{2}$ and C. N. Galdhar ${ }^{3}$ \\ ${ }^{1}$ Department of Veterinary Medicine, College of Veterinary Science \& AH, Durg, \\ Chhattisgarh-491001, India \\ ${ }^{2}$ Department of Veterinary Physiology and Biochemistry College of Veterinary Science \& AH, \\ Durg, Chhattisgarh-491001, India \\ ${ }^{3}$ Department of Veterinary Clinical Medicine, Ethics and Jurisprudence, \\ Bombay Veterinary College, India \\ *Corresponding author
}

\section{A B S T R A C T}

\begin{tabular}{l} 
Ke y w o r d s \\
canine, \\
hypothyroidism, \\
male, labrador, \\
Chhattisgarh \\
\hline Article Info \\
\hline $\begin{array}{l}\text { Accepted: } \\
12 \text { February } 2020 \\
\text { Available Online: } \\
10 \text { March } 2020\end{array}$ \\
\hline
\end{tabular}

The present study was conducted to know the prevalence of canine hypothyroidism in Durg-Bhillai, Raipur and Rajnandgaon districts of Chhattisgarh state. The overall prevalence of hypothyroidism was found to be $1.28 \%$ in Chhattisgarh state with highest prevalence in Raipur (1.73\%) followed by Durg-Bhillai (1.25\%) and Rajnandgaon (0.97\%). Dogs between 6-8 years age $(52.381 \%)$ were more susceptible to hypothyroidism. The prevalence of hypothyroidism was higher in male dogs $(59.52 \%)$ as compared to females (40.48\%). Hypothyroidism in dogs was found to be more prevalent in Labrador breed followed by Golden retriever, Spitz, German Shephard, Pug, Saint Bernard and Rottweiler respectively. Dogs having body weight above $40 \mathrm{~kg}$ were more susceptible for hypothyroidism accounting to a prevalence rate of $57.14 \%$.

\section{Introduction}

Hypothyroidism is the most frequently noticed clinical endocrinopathy in dogs resulting from a lowered production and release of T4 and T3 hormones by the thyroid gland (Ettinger and Feldman, 2000).It can be classified as primary, secondary and tertiary depending upon whether the cause resides in the thyroid gland, pituitary gland or hypothalamus, respectively.Certain breeds namely Golden retrievers, Doberman pinschers and Spaniels are highly predisposed to hypothyroidism. Spayed and neutered dogs are at increased risk of developing hypothyroidism (Lathan, 2012).

The most common clinical characteristics are metabolic signs i.e. lethargy, obesity or weight gain, exercise intolerance, poor wound healingand dermatological abnormalities include alopecia, poor skin and hair coat, hair 
loss/alopecia or abnormal hair turnover, dull and brittle haircoat, hyperpigmentation, oily or dry skin and thickened skin ("myxedema"). The other clinical signs includes behavioural changes, intolerance to cold (seeking of warm places), sad/tragic facial expression, odiferous skin that could be pruritic (itchy) due to secondary bacterial infection, and/or yeast infection, pyoderma (superficial infections) with or without concurrent demodicosis (Panciera, 2001 and Saara, 2011).The diagnosis of canine hypothyroidism is often challenging as clinical signs are slow to onset, vague, non-specific and identified in dogs with other non-thyroidal diseases. Detailed study in of canine hypothyroidism are lacking in India. Further, epidemiological study of hypothyroidism in dogs has not been explored in Chhattisgarh state till date, therefore, keeping in view the above issuethe present study was undertaken to know the prevalence of hypothyroidism in dogs in and around Durg-Bhilai, Raipur and Rajnandgaon districts of Chhattisgarh state.

\section{Materials and Methods}

\section{Prevalence study}

The prevalence of hypothyroidism was calculated taking into account number of total dogs brought to the clinic for various health reasons from March 2018 to February 2020 to the Teaching Veterinary Clinical Complex, College of Veterinary Science \& AH, Durg, District Veterinary hospitals of Durg-Bhillai, Raipur and Rajnandgaon districts of Chhattisgarh state. The prevalence was further analyzed in relation to age, breed sex and body weight.

\section{Diagnosis}

\section{History}

Relevant information was collected by adopting a standardized questionnaire, the owners were enquired about age, signalment, gender, general health, estrous cycles in intact females, libido in male, medications administered during the past three months, exercise and cold intolerance. The information thus obtained was recorded and analyzed. Dogs of all ages, breeds and of either sex were included in the present study.

\section{Clinical examination}

Standardized physical examination of dogs was carried out with special reference to clinical signs of hypothyroidism i.e. dermatological (bilateral symmetrical alopecia, rat tailed appearance, hyper pigmentation, pruritus, pyoderma, seborrhea, erythema, thinning of hair coat), metabolic (lethargy, weight gain, exercise and cold intolerance) and reproductive disorders etc. was performed. The appearance of pelage(hair coat), occurrence of bad odour from the dog, the ease of hair removal from follicle (epilation) and the pattern of lesions on the skin were noted. On the basis of clinical signs and owner's history, dogs with one or more clinical signs (alopecia being the most common) that are suggestive of hypothyroidism were selected and subjected to thyroid hormone estimation for confirmation.

\section{Thyroid function tests}

\section{Collection of samples}

Blood samples from hypothyroidism suspected dogs were collected either from cephalic or saphenous veins aspetically. After collection, blood was allowed to clot at room temperature, and then centrifuged at 1,500 rpm for 10 minutes. Serum was collected and stored at $-20^{\circ} \mathrm{C}$ until further assay. Total triiodothyronine (tT3), total Thyroxine (tT4) and free Thyroxine (fT4) were estimated by Radio immuno assay kits (RIA)(Gnanasekar et al., 2010). 


\section{Results and Discussion}

\section{Prevalence}

Among 3269 dogs examined from March 2018 to February 2020, 42 dogs were found to be positive for hypothyroidism accounting for an overall prevalence rate of 1.28 per cent (42/3269) in Chhattisgarh state. Highest prevalence was recorded in Raipur (1.73\%) followed by Durg-Bhillai (1.25\%) and Rajnandgaon $\quad(0.97 \%)$ districts of Chhattisgarh (Fig.1).

Panciera (1994); Dixon et al., (1999); Rani et al., (2005); Borku and Aktas (2007); Saara (2011): Gulzar et al., (2014); Ziener et al., (2015) and Durga (2017) reported prevalence of hypothyroidism in dogs to be $0.8 ; 0.8,1.14$, $0.6,1.68,0.4,2.7$ and 0.98 per cent respectively. In the present study, the difference noted in the prevalence rate in various districts could be due to variation in the study sample size.

\section{Age wise prevalence of canine hypothyroidism}

The age wise prevalence of hypothyroidism is depicted in Fig.2. Prevalence of hypothyroidism was highest in dogs of 6-8 years age $(52.381 \%, 22 / 42)$ followed by $4-6$ years $(26.19 \%, 12 / 42) \quad(14.28 \%$ in DurgBhillai, $7.142 \%$ in Raipur and $7.142 \%$ in Rajnandgaon) age group, 2-4 years age $(9.52 \%, 4 / 42) \quad(4.762 \%$ in Durg-Bhillai whereas, $2.381 \%$ in Raipur and Rajnandgaon) further, dogs less than 2 years age group (2.381\% in Durg-Bhillai and Rajnandgaon with 00 cases in Raipur) and above 8 years (2.381\% in Durg-Bhillai, 01 in Raipur and nil in Rajn andgaon) age had $2(4.76 \%)$ dogs positive for hypothyroidism in each group.

The findings of the present study were almost in concurrence with those of Lathan (2012);
Das et al., (2013); Tappin (2014) and Durga (2017) who reported higher incidence of hypothyroidism in adult dogs. Ettinger and Feldman (2000) reported that the mean age at diagnosis of hypothyroidism was seven years.

The higher incidence of hypothyroidism in adult dogs might be due to higher concentrations of thyroid hormone during growth and development phase and they progressively declined with advancement of age, hence adult dogs had increased susceptibility for hypothyroidism (Kumar et al., 2012).

\section{Sex wise prevalence of canine hypothyroidism}

The prevalence of hypothyroidism in dogs was highest in male dogs $(59.52 \%, 25 / 42)$ (28.57\% in Durg-Bhillai, $19.05 \%$ in Raipur and $11.904 \%$ in Rajnandgaon) as compared to females 40.48 per cent (17/42) $(19.05 \%$ in Durg-Bhillai, $11.9 \%$ in Raipur and $9.52 \%$ in Rajnandgaon) (Fig. 3) which is in accordance with Durga (2017).

In contrary, Milne and Hayes (1981) and Gulzar et al., (2014) and Durga (2017) recorded higher prevalence in female dogs. However, Vajner et al., (1997); Dixon et al., (1999) and Ghodasara et al., (2013) documented that gender had no influence on the prevalence of hypothyroidism.

\section{Breedwise prevalence of canine hypothyroidism}

The highest prevalence of hypothyroidism wasrecordedin pure-bred dogs88.1 per cent $(42.857 \%$ in Durg-Bhillai, $26.19 \%$ in Raipur and 19.047 in Rajnandgaon) as compared to non-descript dogs 11.9 per cent $(4.762 \%$ in Durg-Bhillai and Raipur whereas, $2.381 \%$ in Rajnandgaon respectively) (Fig. 4). 
In the present study, the highest prevalence of canine hypothyroidism was noted in Labrador $(50.00 \%, 21 / 42)(23.81 \%$ in Durg-Bhillai, $16.67 \%$ in Raipur and $9.523 \%$ in Rajnandgaon) (Fig. 5).

The prevalence in other breeds was as follows: Golden retriever $(9.523 \%$ in DurgBhillai followed by $4.762 \%$ in Raipur and Rajnandgaon respectively) whereas, Spitz had prevalence rate of 9.523 per cent $(4.762 \%$ in Durg-Bhillai with $2.381 \%$ in Raipur and Rajnandgaon) and German Shephard (9.523\%) (4.762\% in Durg-Bhillai and $2.381 \%$ in Raipur and Rajnandgaon) were diagnosed with canine hypothyroidism.

Three dogs of Pug breed (7.143\%) $(4.762 \%$ in Durg-Bhillai, nil in Raipur and $2.381 \%$ in Rajnandgaon) had hypothyroidism. Single $\operatorname{dog}(2.381 \%)$ each of Saint Bernard $(2.381 \%$ in Raipur withnil cases in Durg-Bhillai and Rajnandgaon) and Rottweiler $(2.381 \%$ in Raipur with 00 cases in Durg-Bhillai and
Rajnandgaon) showed canine hypothyroidism.

In the present study, Labrador were found to be highly prevalent to canine hypothyroidism which is in accordance with Gulzar et al., (2014). High risk of hypothyroidism in Golden Retrievers, Doberman Pinschers, Great Danes, Pomeranians, Poodles, Boxers and Daschunds was previously reported by Panciera (1994); Dixon et al., (1999) and Daminet et al., (2003).

Van Geffen et al., (2006) and Saara (2011) also documented the genetic predisposition of hypothyroidism and reported that the serum thyroxine concentrations varied between breeds. This variation could be probably due to habitation of different breeds in different geographical regions. However, as the number of dogs screened for hypothyroidism was limited in the present study, generalized conclusions could not be drawn with regards to breed predilection.

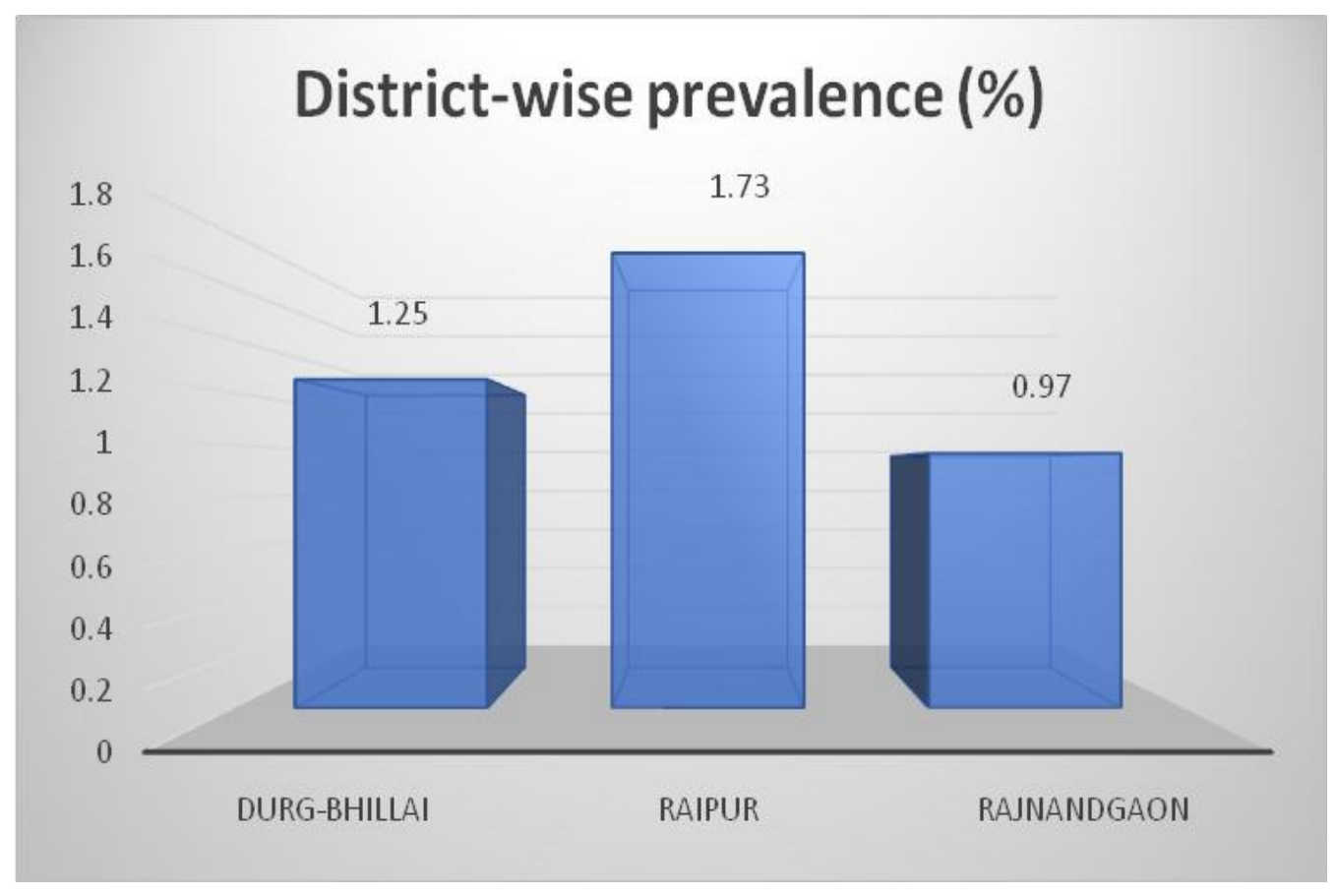

Fig.1 District wise prevalence of canine hypothyroidism 


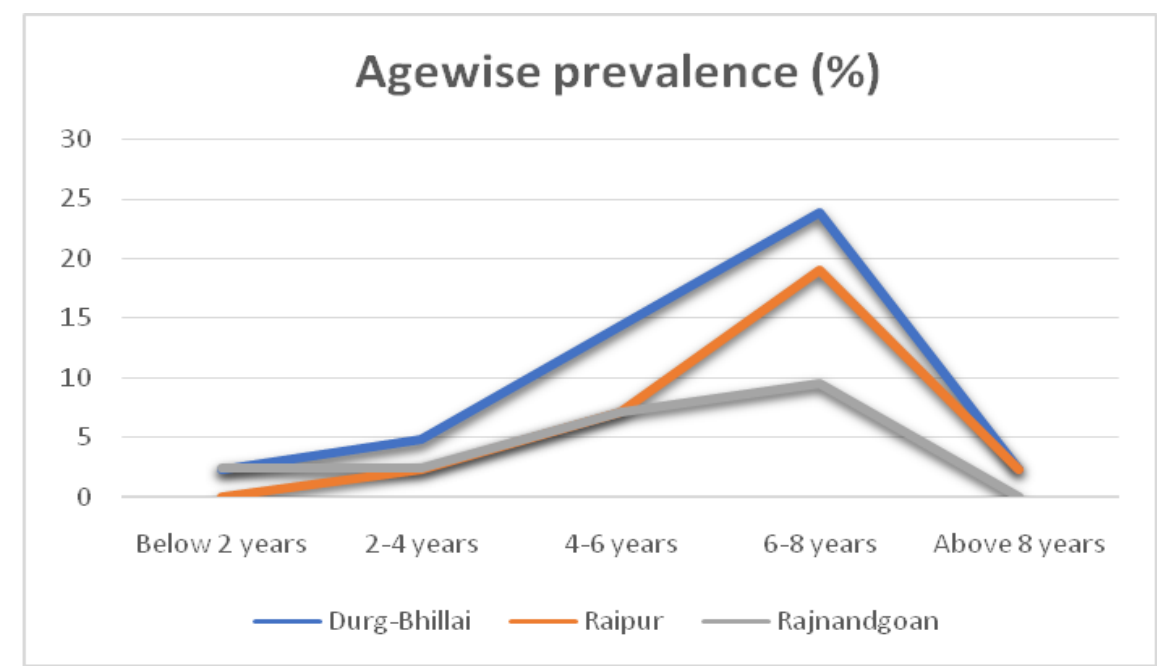

Fig.2 Agewise prevalence of canine hypothyroidism

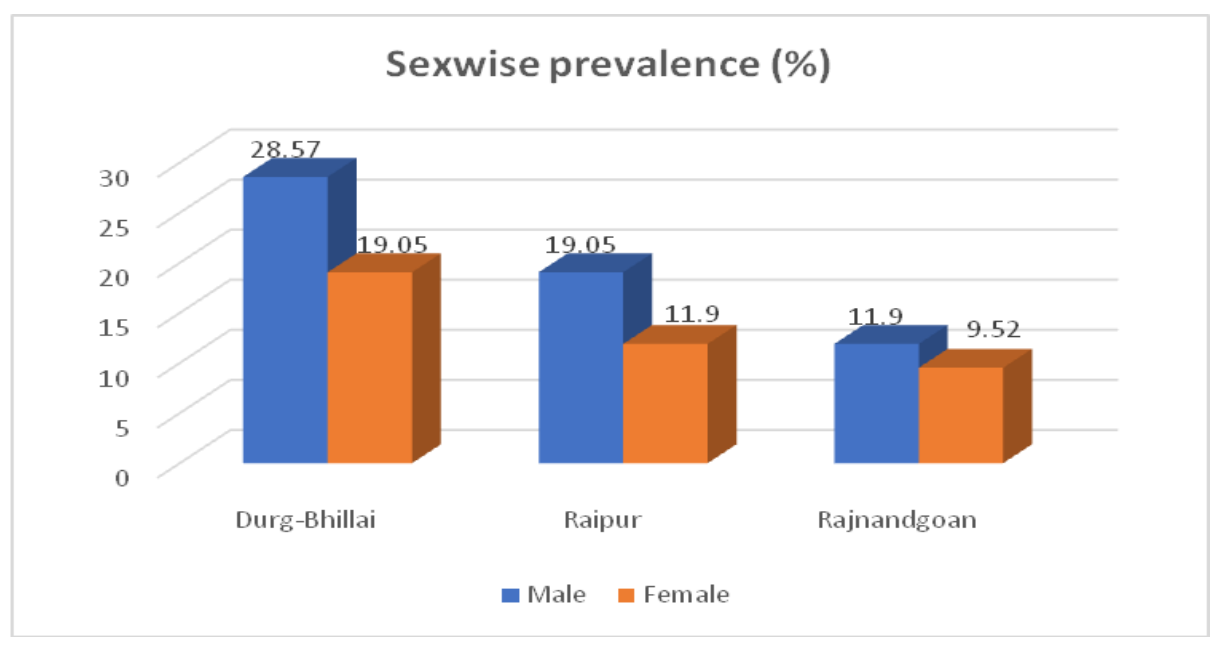

Fig.3 Sexwise prevalence of canine hypothyroidism

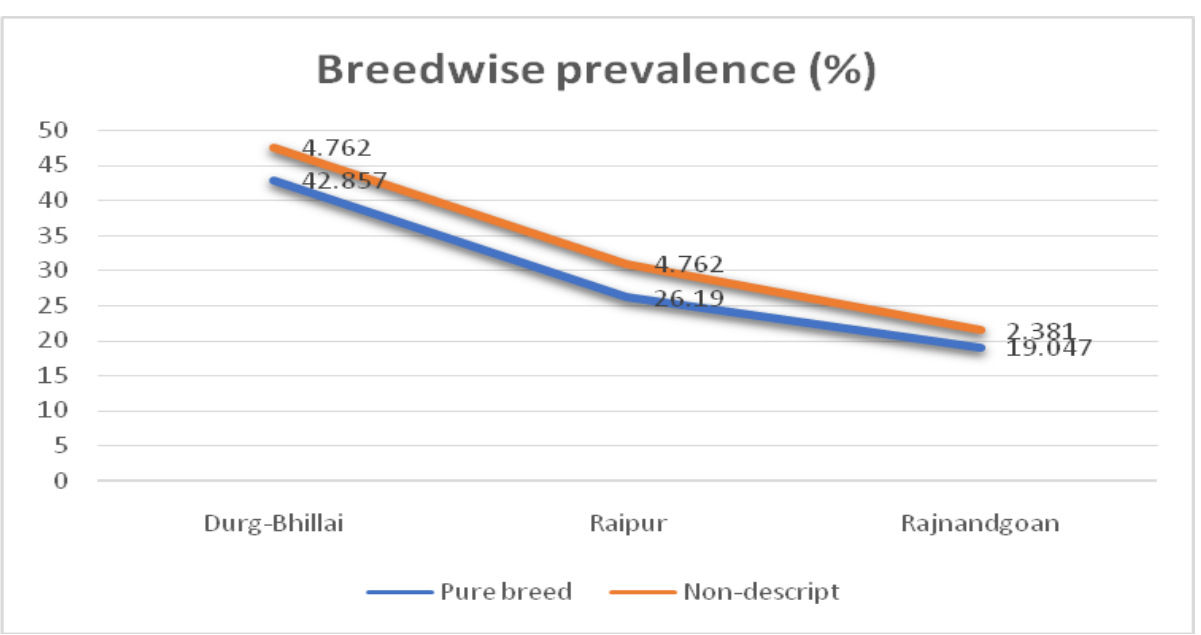

Fig.4 Breedwise prevalence of canine hypothyroidism 


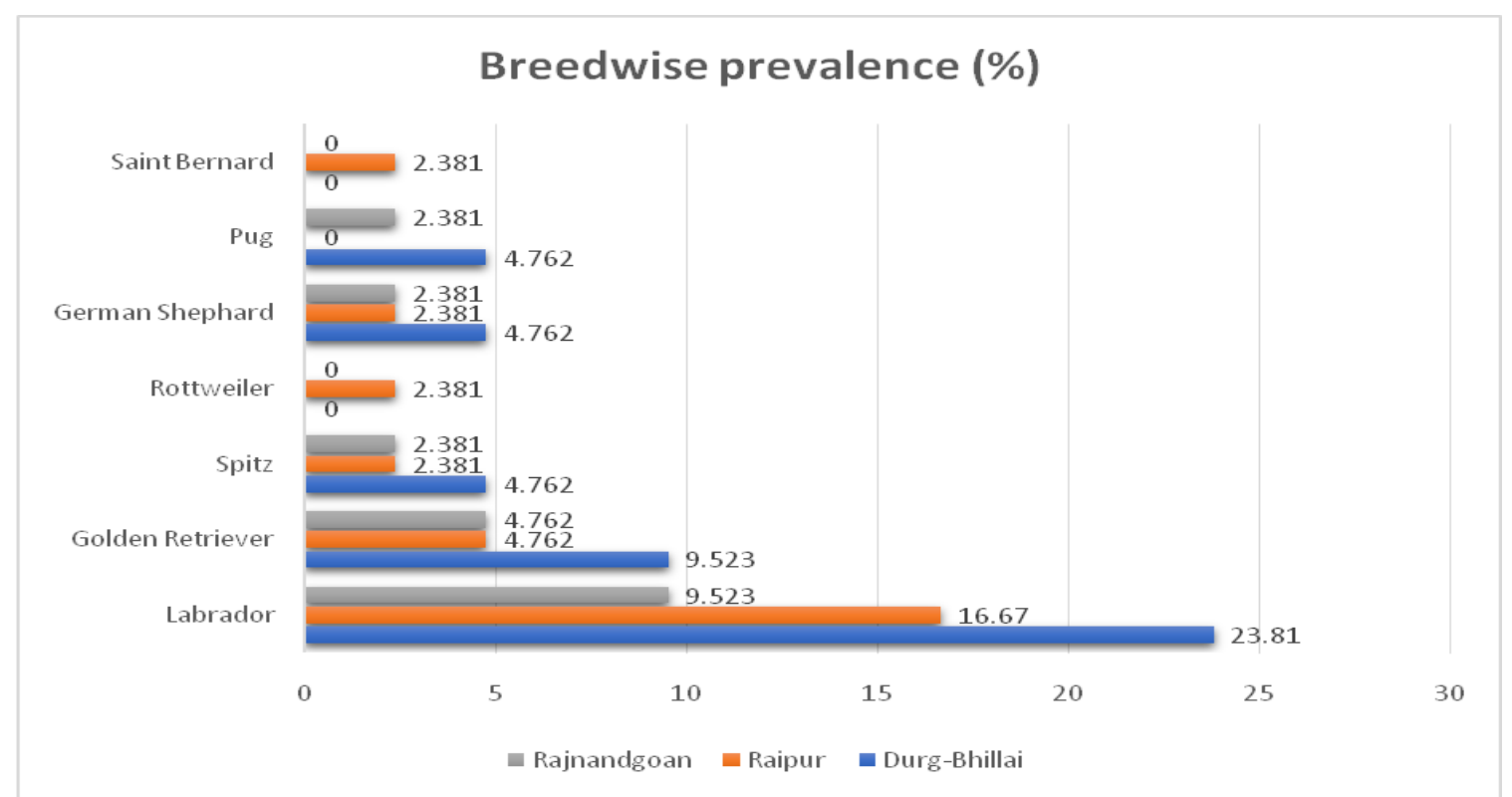

Fig.5 Breedwise prevalence of canine hypothyroidism

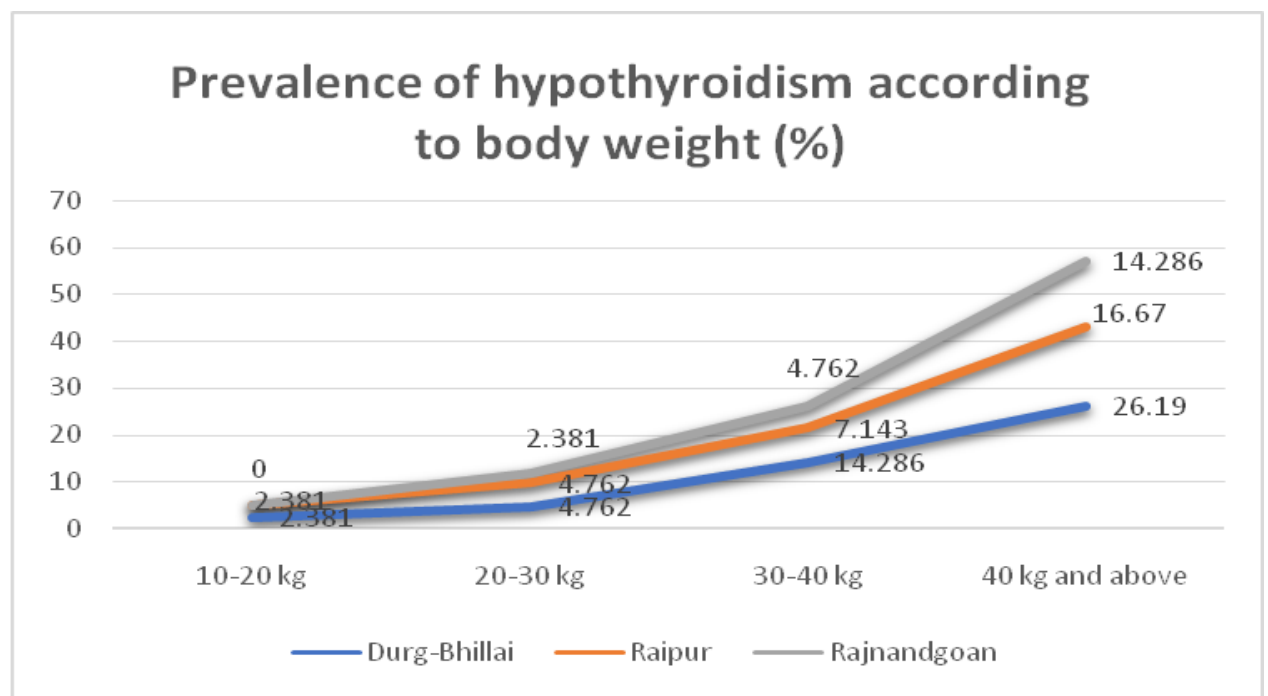

Fig.6 Prevalence of canine hypothyroidism according to body weight

Prevalence of hypothyroidism according to body weight

The occurrence of hypothyroidism in dogs with different body weights is depicted in Fig. 6. Dogs with body weight above $40 \mathrm{~kg}$ were found to be more susceptible for hypothyroidism as $24 / 42(57.14 \%)(26.19 \%$ in Durg-Bhillai, $16.67 \%$ in Raipur and $14.286 \%$ in Rajnangaon). The numbers of positive cases were 11/42 (26.190\%), 05/42 $(11.904 \%)$ and two $(4.76 \%)$ in dogs with body weights of 30-40 kg (14.286\% in DurgBhillai, $7.143 \%$ in Raipur and $4.762 \%$ in Rajnandgaon), 20-30 kg (4.76\% in DurgBhillai and Raipur whereas, $2.381 \%$ in Rajnandgaon) and 10-20 kg (2.381\% in DurgBhillai and Raipur with nil cases recorded in Rajnandgaon) respectively. The results are in corroboration with the findings of Dixon et al., (1999) and Gulzar et al., (2014). Dixon et al., (1999) reported obesity in $41 \%$ to $48 \%$ hypothyroid dogs. Nachreiner et al., (2002) observed a significant correlation between 
body weight and hypothyroidism. This signifies the importance of examining thyroid function in obese dogs to avoid failure of any nutritional treatment.Obesity and hypothyroidism are two common clinical conditions that have been linked together closely. The link has become more relevant in the context of an unprecedented rise in the prevalence of obesity worldwide (Reimers, 1990 and Sanyal and Moutusi, 2016).

\section{References}

Borku, M.K. and Aktas, M.S.(2007). Hypothyroidism in dogs. Veteriner Hekimler Dernegi Dergisi, 78: 47-52.

Daminet, S., Croubels, L., Duchateau, A., Debunne, C., van Geffen, Y., Hoybergs, H., vanBree. and A, de Rick.(2003). Influence of acetylsalicylic acid and ketoprofen on canine thyroid function tests. Veterinary Journal, 166: 224-232.

Das, M., Kumar, S. and Pradhan, N. R.(2013). Hypothyroidism associated with dermatologic affections and its therapeutic management. Intas Polivet, 14: 436-37.

Debmalya,

Sanyal. and Moutusi, Raychaudhuri.(2016). Hypothyroidism and obesity: An intriguing link. Indian J Endocrinol Metab, 20(4): 554-557.

Dixon, R.M., Reid, S.W. and Mooney, C.T. (1999). Epidemiological, clinical, haematologicaland biochemical characteristics of canine hypothyroidism. Veterinary Record, 145: 481-487

Durga, (2017). Clinico-diagnostic and therapeutic studies on hypothyroidism in dogs. M.V.Sc thesis submitted to Sri Venkateswara Veterinary University, Tirupathi.

Ettinger, S. J. and Feldman, E. C. (2000) Textbook of Veterinary Internal Medicine, Diseases of the Dog and Cat, 5th ed. Philadelphia, WB Saunders, pp:1420-1427.

Ghodasara, S. N., Savsan, H. H., Kalaria, V. A., Bhadaniya, A. R. and Odedra, M. D.(2013). Clinico-therapeutics of hypothyrodism in a Labrador dog. Intas Polivet, 14: 432- 435.

Gnanasekar, R., Nagvekar,U. H. and Sivaprasad, N. (2010). Development andvalidation of a two-step free thyroxine radioimmunoassay based on antibody coatedtubes. Journal of Liquid Chromatography \& Related Technologies. 33:1576-1586.

Gulzar, S., R. Khurana, D.Agnihotri, A. Aggarwal and G. Narang. (2014). Prevalence of hypothyroidism in dogs in Haryana. Indian J.Vet. Res, 23(1): 19.

Kumar, K. S., Srikala, D. and Rao, D. S. T.(2012). Hypothyroidism -A cause for dilated cardiomyopathy in dogs: four year study. Veterinary World, 5: 742747.

Lathan, P.(2012). Canine Hypothyroidism. Clinician's Brief Missisipi State University. pp. 25-28.

Milne, K. L. and Hayes, H. M.(1981). Epidemiologic features of canine hypothyroidism. The Cornell Veterinarian, 71: 3-14.

Nachreiner, R. F., Refsal, K. R., Graham, P. A. and Bowman, M. M.(2002). Prevalence of serum thyroid hormone autoantibodies in dogs with clinical signs of hypothyroidism. Journal of American Veterinary Medical Association, 220: 466-471.

Panciera, D. L.(1994). Hypothyroidism in dogs: 66 cases (1987-1992). Journal of the American Veterinary Medical Association, 204: 761-767.

Panciera, D. L.(2001). Conditions associated with canine hypothyroidism. Veterinary Clinics of North America Small Animal Practice, 31: 935-950.

Rani, S., Yathiraj, S., Kamran, C. A., Ravi, R. 
D. and Sudha, G.(2005). Diagnosis of hypothyroidism based on T3 and FT4 in: Proceedings of National Symposium on Advancement for Improving Animal Health and Protection and XXIII Annual convention of the Indian Society for Veterinary Medicine, $2^{\text {nd }}$ to $4^{\text {th }}$ February 2005. pp. 69.

Reimers, T. J., Lawler, D. F. and Sutaria, P. M.(1990). Effects of age, sex, and body size on serum concentrations of thyroid and adrenocortical hormones in dogs. American Journal of Veterinary Research, 51: 454-457.

Saara, K.(2011). Hypothyroidism in Spanish Water Dogs in Finland. Licentiate Thesis in Veterinary Medicine, University of Helsinki, Finland.

Tappin, S.(2014) Canine hypothyroidism making a definitive diagnosis.
Veterinary Ireland Journal, 4: 483-488. Vajner, L., Vortel, V. and Brejcha, A.(1997). Lymphocytic thyroiditis in Beagle dogs in a breeding colony: histological findings. Veterinarni Medicina, 42: 4349.

Van Geffen, C., Bavegems, V., Duchateau, L., De Roover, K. and Daminet, S.(2006). Serum thyroid hormone concentrations and thyroglobulin auto antibodies in trained and non-trained healthy whippets. Veterinary Journal, 172: 135-140.

Ziener, M. L., Dahlgren, S., Thoresen, S. I. and Lingaas, F.(2015). Genetics and epidemiology of hypothyroidism and symmetrical onychomadesis in the Gordon setter and the English setter. Canine Genetics and Epidemiology, 2: 12.

\section{How to cite this article:}

Roopali, B., S. Roy, M. Roy and Galdhar. C. N. 2020. Epidemiological Study of Canine hypothyroidism in Chhattisgarh state, India. Int.J.Curr.Microbiol.App.Sci. 9(03): 1432-1439. doi: https://doi.org/10.20546/ijcmas.2020.903.167 